\title{
Terrestrial Essential Climate Variables (ECVs) at a Glance
}

The Global Terrestrial Observing System (GTOS), Global Climate Observing System (GCOS) World Meteorological Organization (WMO), and Committee on Earth Observation Satellites (CEOS) all support consistent global land observations and measurements. To accomplish this goal, GCOS defined Essential Climate Variables (ECVs) as measurements of atmosphere, oceans, and land that are technically and economically feasible for systematic observation and that are needed to meet the United Nations Framework Convention on Climate Change and requirements of

the Intergovernmental Panel on Climate Change. The following are the climate variables defined by GCOS that relate to terrestrial measurements. Several of them are currently measured most appropriately by in-place observations, whereas others are suitable for measurement by remote sensing technologies. The U.S. Geological Survey is the steward of the Landsat archive, satellite imagery collected from 1972 to the present, that provides a potential basis for deriving long-term, global-scale, accurate, timely and consistent measurements of many of these ECV
